\title{
Screening of composite substrates suitable for tissue-cultured plantlets growth of Asparagus cochinchinensis (Lour.) Merr
}

\author{
Xiaosong Yu, Lin Li, Yongquan Li, Zhi Liu, Ningxian Yang, \\ Mingsheng Zhang*
}

Key Laboratory of Plant Resource Conservation and Germplasm Innovation in Mountainous Region (Ministry of Education), College of Life Sciences, Guizhou University, Guiyang, Guizhou 550025, China

\begin{abstract}
Asparagus cochinchinensis (Lour.) Merr is a medicinal, edible and horticulture plant. Seedling breeding relies on tissuecultured technology, but the transplant from tissue-cultured seedlings to field cultivation poses a problem in the large-scale production of $A$. cochinchinensis. Tissue-cultured seedlings of $A$. cochinchinensis were used as materials, and they were transplanted into the substrates that were mixed with coconut bran, peat, vermiculite, perlite or garden soil. The analysis of the physical and chemical properties of the substrate, combined with the survival rate of seedlings, the aboveground parameters (plant height, stem diameter, fresh weight and dry weight), underground parameters (root fresh weight, root dry weight, root length, root diameter, root surface area and root volume) and physiological indexes (malondialdehyde, soluble protein, soluble sugar, proline, chlorophyll and root vigour), allow us to understand the effects of different combination substrates on the growth and physiology of $A$. cochinchinensis tissue-cultured seedlings. We concluded that the survival rate of seedlings was negatively correlated with the bulk density and conductivity and was positively correlated with the porosity in the substrate. The membership function was used to comprehensively evaluate the indexes of each combination substrate, and it was concluded that coconut bran:perlite:vermiculite $=33.33 \%: 33.33 \%: 33.33 \%$ (bulk density $=0.23 \mathrm{~g} \cdot \mathrm{cm}^{-3}$, total porosity $=65.07 \%, \mathrm{pH}=6.30$, conductivity $=0.51 \mathrm{mS} \cdot \mathrm{cm}^{-1}$ ) scored the highest, the survival rate of seedlings reached $87.10 \%$, the aboveground and underground growth were vigorous and the quality was better than other substrates. This research provides technical support for the efficient cultivation of tissue-cultured seedlings of A. cochinchinensis and reduces the cost of raising seedlings.
\end{abstract}

Keywords: aboveground growth, combined substrate, physiology and biochemistry, underground growth

\section{INTRODUCTION}

Asparagus cochinchinensis (Lour.) Merr is a perennial plant (Liliaceae), whose dry root tubers are used in traditional Chinese medicine, where it is known as Tiandong. The root of $A$. cochinchinensis (RAC) has been used to treat fever, cough, kidney diseases and benign breast tumours (Zhang et al., 2015). Pharmacological studies on this plant have demonstrated antioxidant, anti-tumour and antiinflammatory activities (Lee et al., 2009; Chun et al., 2011; Lei et al., 2017). It is also often made as candied fruit, porridge, wine, etc. and has a unique healthcare effect (Zhang et al., 2015; Wang et al., 2019); because of its delicate plant shape and evergreen nature throughout the seasons, it is used as a horticulture plant. Therefore,

*Corresponding author.

e-mail: mszhang@163.com (Mingsheng Zhang). 
A. cochinchinensis is an excellent plant that integrates medicinal, ornamental and edible purposes and has huge market potential. In recent years, as the wild resources of A. cochinchinensis have declined, the market demand has continued to rise. With the development of tissue-cultured technology, A. cochinchinensis tissuecultured and rapid propagation technology have made some progress, and it has become the first choice for seedling breeding (Asmari et al., 2004). At present, many researchers have made some progress in the tissue culture of $A$. cochinchinensis through different organs. For example, Jiang et al. (2013) used plant hypocotyls as materials for in-vitro culture. Choo et al. (2005) cultured A. cochinchinensis in vitro with shoot tip. Kim et al. (2021) based their research on indirect organisation and used leaf segments cut from seeds of in-vitro germinated seeds for tissue culture. Meanwhile, our laboratory also achieved good seedling raised by using seeds as explants direct to tissue culture (Li et al., 2021). However, the transition link from tissuecultured seedlings to field cultivation is still a problem in the large-scale production of $A$. cochinchinensis. The selection of the cultivation substrate is one of the key factors determining the survival rate of transplants. There are few research reports on the selection of planting substrate and its effect on the growth of tissuecultured seedlings of $A$. cochinchinensis.

A. cochinchinensis likes a warm and humid environment and climate and is resistant to drought and cold. It is wild in the low-mountain sparse forest, hillside grass, bush and other environments (Lim, 2015), which means that the cultivation substrate needs to have good air permeability and water retention to provide good water, gas, fertiliser, $\mathrm{pH}$ value and other conditions for root growth. Single-garden soil cultivation will greatly reduce the survival rate. Therefore, the development of a substrate material with stable physical and chemical properties, low cost and convenient materials is of great significance to the protection of A. cochinchinensis's resources and the healthy development of substrate cultivation. The substrate is a carrier that can provide water and nutrition for crop roots, which directly affects the production cost, seedling quality and comprehensive production capacity after planting. At present, peat, coconut bran, perlite and vermiculite are widely used and have ideal seedling raising effects (Ma et al., 2020). Although peat has the characteristics of high content of organic matter and humic acid, rich fibre, loose and porous nature, good ventilation and water permeability, due to its non-renewability and irreversible damage to the ecological environment due to large-scale development (Abad et al., 2001), at the same time, its inherent hydrophobicity brings inconvenience to the transportation and application of peat substrate (Du et al., 2020). Coconut bran is a kind of natural organic substance, which is the fibre powder of coconut shell and has the advantages of convenient storage and transportation, slow degradation rate and strong buffering ability. As a substrate, it has better ventilation and water retention than ordinary matrices, and it is cheap and easy to obtain (Meerow, 1995). However, coconut bran has high salt content and cannot provide nutrients to plants (Liu et al., 2013). Perlite and vermiculite can only be used as auxiliary substrates in horticultural cultivation. So, different configurations of substrates are required to further improve the survival rate and growth of tissue-cultured seedlings and then to quickly obtain a large number of healthy and highquality seedlings.

In this study, a variety of raw materials (garden soil, coconut bran, peat, perlite and vermiculite) were combined. We compared the growth of tissue-cultured seedlings of $A$. cochinchinensis in different combined substrates, tissue-cultured the aboveground morphology, underground morphology and physiological indexes were taken as the evaluation criteria, in order to screen the appropriate cultivation substrate, provide technical support for the efficient cultivation of tissue-cultured seedlings of A. cochinchinensis and reduce the seedling cost.

\section{MATERIALS AND METHODS}

\section{Seedlings}

The seedlings grew in the culture bottle by tissue culture, and the seed hypocotyl was the explant. The medium of callus induction was Murashige and Skoog (MS) + 6-Benzylaminopurine (6-BA) $1.0 \mathrm{mg} \cdot \mathrm{L}^{-1}+1$-naphthaleneacetic acid (NAA) $0.5 \mathrm{mg} \cdot \mathrm{L}^{-1}$; the proliferation medium of callus was $\mathrm{MS}+6$-BA $0.5 \mathrm{mg} \cdot \mathrm{L}^{-1}+\mathrm{NAA} 2.0 \mathrm{mg} \cdot \mathrm{L}^{-1}$; the induction medium of clustered buds was $\mathrm{MS}+6-\mathrm{BA}$ $0.5 \mathrm{mg} \cdot \mathrm{L}^{-1}+\mathrm{NAA} 0.1 \mathrm{mg} \cdot \mathrm{L}^{-1}+\operatorname{Kinetin}(\mathrm{KT})$ $0.1 \mathrm{mg} \cdot \mathrm{L}^{-1}$; the suitable medium for strong seedlings was $\mathrm{MS}+6$-BA $0.2 \mathrm{mg} \cdot \mathrm{L}^{-1}+$ indole-3-acetic acid (IAA) $1.0 \mathrm{mg} \cdot \mathrm{L}^{-1}$; and the suitable rooting medium was $1 / 2 \mathrm{MS}+\mathrm{NAA} 2.0 \mathrm{mg} \cdot \mathrm{L}^{-1}$ (Li et al., 2021). The average seedling height was $6.82 \pm 0.52 \mathrm{~cm}$, with a stem diameter of $0.74 \pm 0.10 \mathrm{~mm}$ and more than two roots in the Key Laboratory of Plant Resource Conservation and Germplasm Innovation in Mountainous Region (Ministry of Education) of Guizhou University (Guizhou, China).

\section{Substrate type}

In the experiment, garden soil, coconut bran, peat, perlite and vermiculite were mixed according to a certain volume ratio to make seven combination substrates (Table 1). Among them, T1 is the control; T2, T3, T4 and T5 are the mixture of different raw materials and soil; and $\mathrm{T} 6$ and $\mathrm{T} 7$ are the soilless cultivation of different raw materials. The garden soil used was from Huaxi land (Guiyang, China); the coconut bran used was from Galuku (Sydney, Australia); the peat used was from Pindstrup (Shanghai, China); the perlite used was from Xinyang Jinhualan Mining Co., Ltd (Xinyang, China); and the vermiculite used was from Shijiazhuang Chenxing Industrial Co., Ltd (Shijiazhuag, China). 


\section{Substrate properties}

The air-dried substrates were collected before transplanting and planting, and the bulk density, total porosity, aeration porosity, water retaining porosity, void ratio, $\mathrm{pH}$ and electrical conductivity (EC) were determined according to the method of Shi et al. (2016). The physical and chemical properties of each combined substrate are shown in Table 2.

\section{Experimental design}

The tissue-cultured seedlings were transplanted in plastic nutrient pots with a diameter of $17 \mathrm{~cm}$ and a height of $16 \mathrm{~cm}$. Three plants were planted in each pot, each had treatment was 30 pots. Place outdoors, water uniformly every 7 days.

After the tissue-cultured seedlings of $A$. cochinchinensis were planted, three plants with basically a similar growth trend were selected from each treatment every 15 days. Plant height and stem diameter were measured with a ruler. Plants were washed under running water to measure fresh and dry weights. Fresh weight was measured with a balance. The dry weight determination method was to put the plants in an oven at $105{ }^{\circ} \mathrm{C}$ for $20 \mathrm{~min}$ and then bake them to constant weight at $70{ }^{\circ} \mathrm{C}$. EPSON Expression

Table 1. Combination ratio of different substrates.

\begin{tabular}{lccccc}
\hline Code & \multicolumn{5}{c}{ Volume ratio (\%) } \\
\cline { 2 - 6 } & $\begin{array}{c}\text { Garden } \\
\text { soil }\end{array}$ & Perlite & $\begin{array}{c}\text { Coconut } \\
\text { bran }\end{array}$ & Vermiculite & Peat \\
\hline T1 & 100.00 & 0 & 0 & 0 & 0 \\
T2 & 20.00 & 40.00 & 40.00 & 0 & 0 \\
T3 & 20.00 & 0 & 40.00 & 40.00 & 0 \\
T4 & 20.00 & 0 & 0 & 40.00 & 40.00 \\
T5 & 20.00 & 40.00 & 0 & 0 & 40.00 \\
T6 & 0 & 33.33 & 33.33 & 33.33 & 0 \\
T7 & 0 & 33.33 & 0 & 33.33 & 33.33 \\
\hline
\end{tabular}

T1: garden soil 100\%; T2: garden soil:perlite:coconut bran $=20 \%$ : 40\%:40\%; T3: garden soil:coconut bran:vermiculite $=20 \%: 40 \%: 40 \%$; T4: garden soil:vermiculite:peat $=20 \%: 40 \%: 40 \%$; T5: garden soil: perlite:peat $=20 \%: 40 \%: 40 \%$; T6: perlite:coconut bran:vermiculite $=$ $33.33 \%: 33.33 \%: 33.33 \%$; T7: perlite:vermiculite:peat $=33.33 \%$ : $33.33 \%: 33.33 \%$.
10000XL root scanner (Japan) and its supporting Win RHIZO Pro 5.0 root analysis software were used to determine root characteristic parameters such as total root length, root surface area, root volume and root diameter.

Sixty days after planting, plants were grown into stability and survival rates were counted. Three plants with basically similar growth were selected from each treatment to determine the physiological and biochemical values. Total soluble protein content was determined by the method of Bradford (1976), using bovine serum albumin (BSA) (Takara, Beijing, China) as standard. Proline content determination was performed according to the method of Bates et al. (1973). Soluble sugar content was measured based on the anthrone method (Morris, 1948). Malondialdehyde (MDA) content was determined by the thiobarbituric acid reaction according to Heath and Packer (1968). Total chlorophyll as well as chlorophyll $a$ and $b$ concentrations were determined according to Arnon (1949). Root vigour was measured by the triphenyl tetrazolium chloride (TTC) (Leagene, China) method (Zhou et al., 2018). Each indicator was measured with fresh samples and the observation was repeated thrice.

\section{Statistical analysis}

Data obtained were subjected to statistical analysis using analysis of variance (ANOVA) procedures to test the significant effect of all the variables investigated, using IBM SPSS Statistics version 26. Means were separated using Duncan Multiple Range Test (DMRT) as the test of significance at $p<0.05$. Excel 2016 and Origin 2018 were used for mapping.

Using the method of membership function in fuzzy math, the membership values of each index in seven different combination substrates were calculated, and the membership values of each index were accumulated to obtain the average value. The adaptability of A. cochinchinensis in different combination substrates was comprehensively evaluated (Wang et al., 2021).

If there was a positive correlation between the indexes, we used $\mathrm{X}=\left(\mathrm{X}_{\mathrm{i}}-\mathrm{X}_{\min }\right) /\left(\mathrm{X}_{\max }-\mathrm{X}_{\min }\right)$ to calculate the specific membership function value of each index under each combined substrate.

Table 2. The physical and chemical properties of different substrates combinations.

\begin{tabular}{|c|c|c|c|c|c|c|c|}
\hline \multirow[t]{2}{*}{ Code } & $\begin{array}{l}\text { Bulk density } \\
\left(\mathrm{g} \cdot \mathrm{cm}^{-3}\right)\end{array}$ & $\begin{array}{c}\text { Total porosity } \\
(\%)\end{array}$ & $\begin{array}{c}\text { Aeration } \\
\text { porosity }(\%)\end{array}$ & $\begin{array}{c}\text { Water retaining } \\
\text { porosity }(\%)\end{array}$ & Void ratio & $\begin{array}{c}\mathrm{EC} \\
\left(\mathrm{mS} \cdot \mathrm{cm}^{-1}\right) \\
\end{array}$ & $\mathrm{pH}$ \\
\hline & \multicolumn{7}{|c|}{ Means \pm SD } \\
\hline $\mathrm{T} 1$ & $0.98 \pm 0.03 \mathrm{a}$ & $42.67 \pm 0.57 \mathrm{e}$ & $7.44 \pm 0.10 \mathrm{e}$ & $35.25 \pm 0.67 \mathrm{~d}$ & $0.21 \pm 0.01 \mathrm{e}$ & $1.60 \pm 0.02 \mathrm{a}$ & $5.79 \pm 0.01 \mathrm{e}$ \\
\hline $\mathrm{T} 2$ & $0.38 \pm 0.00 \mathrm{~cd}$ & $55.58 \pm 1.20 \mathrm{~d}$ & $13.16 \pm 0.64 \mathrm{~d}$ & $42.42 \pm 0.98 \mathrm{bc}$ & $0.31 \pm 0.01 \mathrm{~cd}$ & $0.78 \pm 0.01 \mathrm{~b}$ & $5.93 \pm 0.08 \mathrm{~d}$ \\
\hline $\mathrm{T} 3$ & $0.46 \pm 0.01 \mathrm{~b}$ & $59.19 \pm 2.09 \mathrm{bc}$ & $11.10 \pm 0.46 \mathrm{~d}$ & $48.09 \pm 2.55 \mathrm{a}$ & $0.23 \pm 0.02 \mathrm{de}$ & $0.67 \pm 0.02 \mathrm{c}$ & $5.98 \pm 0.04 \mathrm{~cd}$ \\
\hline $\mathrm{T} 4$ & $0.43 \pm 0.03 \mathrm{bc}$ & $59.31 \pm 2.73 \mathrm{bc}$ & $16.12 \pm 0.87 \mathrm{c}$ & $43.18 \pm 3.60 \mathrm{~b}$ & $0.38 \pm 0.05 \mathrm{c}$ & $0.60 \pm 0.03 \mathrm{~d}$ & $6.08 \pm 0.04 \mathrm{~b}$ \\
\hline T5 & $0.36 \pm 0.00 \mathrm{~d}$ & $57.60 \pm 0.47 \mathrm{c}$ & $19.39 \pm 1.45 b$ & $38.21 \pm 1.91 \mathrm{~cd}$ & $0.51 \pm 0.06 \mathrm{ab}$ & $0.51 \pm 0.02 \mathrm{e}$ & $6.06 \pm 0.03 \mathrm{bc}$ \\
\hline T6 & $0.23 \pm 0.05 \mathrm{e}$ & $65.07 \pm 0.61 \mathrm{a}$ & $21.30 \pm 1.25 \mathrm{ab}$ & $43.77 \pm 0.65 \mathrm{ab}$ & $0.49 \pm 0.04 \mathrm{~b}$ & $0.51 \pm 0.01 \mathrm{e}$ & $6.30 \pm 0.01 \mathrm{a}$ \\
\hline $\mathrm{T} 7$ & $0.24 \pm 0.03 \mathrm{e}$ & $62.01 \pm 1.90 \mathrm{ab}$ & $22.72 \pm 0.86 \mathrm{a}$ & $39.29 \pm 1.03 \mathrm{bcd}$ & $0.58 \pm 0.01 \mathrm{a}$ & $0.49 \pm 0.01 \mathrm{f}$ & $6.32 \pm 0.02 \mathrm{a}$ \\
\hline
\end{tabular}

Different lowercase letters in the same column indicate significant differences between treatments $(p<0.05)$.

EC, electrical conductivity. 
If there was a negative correlation between the indexes, we used $X=1-\left(X_{i}-X_{\min }\right) /\left(X_{\max }-X_{\min }\right)$ to calculate the specific membership function value of each index under each combined substrate.

\section{RESULTS}

\section{Survival rate}

The main task of substrate screening was a high survival rate. The effects of different combinations of substrates on the survival rate of tissue-cultured seedlings of $A$. cochinchinensis are shown in Figure 1. This study found that the number of plant survival rate in T6 and T7 combinations of substrates was the largest $(87.1 \%$ and $87.5 \%)$, while the number of deaths in $\mathrm{T} 1$ substrate was less $(61.29 \%)$. The survival rate in each combination of substrates was significantly different from that in the whole garden soil (T1) $(p<0.05)$, indicating that the survival rate of $A$. cochinchinensis tissue-cultured seedlings is low when garden soil is used alone.

\section{Aboveground}

The effect of different combinations of substrates on the growth of $A$. cochinchinensis tissue-cultured seedlings is shown in Figure 2. It can be seen that with the increase of time, the aboveground biomass of $A$. cochinchinensis in each combination substrate has increased. After 60 days of transplanting, the plant

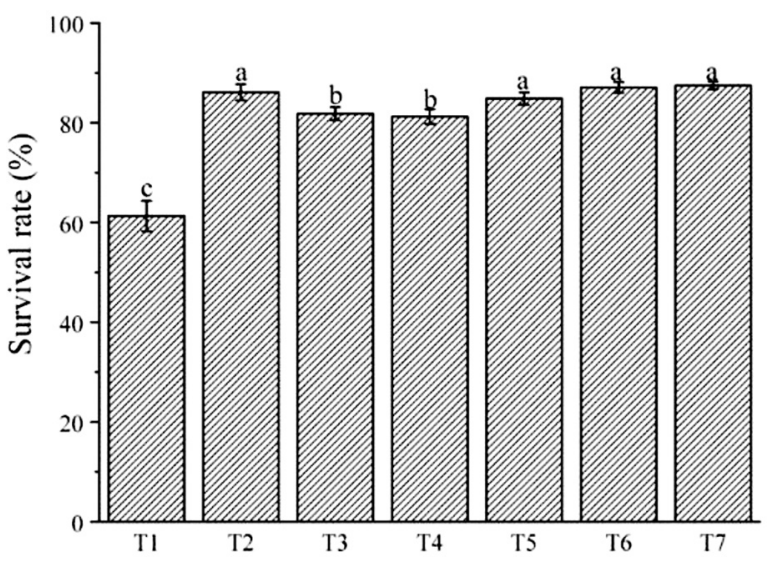

Figure 1. The effect of different combinations of substrates on the survival rate of $A$. cochinchinensis plantlets. Different lowercase letters indicate significant differences between treatments $(p<0.05)$. Error bars represent SD and data in the graphs are the means \pm SD. T1: garden soil 100\%; T2: garden soil:perlite:coconut bran $=20 \%: 40 \%: 40 \% ;$ T3: garden soil:coconut bran:vermiculite $=20 \%: 40 \%: 40 \% ; \quad \mathrm{T} 4:$ garden soil:vermiculite:peat $=20 \%: 40 \%: 40 \% ;$ T5: garden soil:perlite:peat $=20 \%: 40 \%: 40 \%$; T6: perlite:coconut bran:vermiculite $=33.33 \%: 33.33 \%: 33.33 \%$; 7 : perlite:vermiculite:peat $=33.33 \%: 33.33 \%: 33.33 \%$. SD, standard deviation. height of T2 increased the most, at $19.5 \mathrm{~cm}$, followed by T7, with a plant height of $17.13 \mathrm{~cm}$. The growth of T1 was the smallest and was significantly different from other treatments $(p<0.05)$, and its plant height was $8.03 \mathrm{~cm}$. The stem diameter under each combination substrate was between $0.85 \mathrm{~mm}$ and $0.92 \mathrm{~mm}$ but was not significant. The fresh weight and dry weight of the aboveground reached the maximum in the T6 combination medium, attaining values of $1.87 \mathrm{~g}$ and $0.49 \mathrm{~g}$, respectively, which were significantly different from those of other combination substrates. In summary, it is shown that using garden soil alone as the cultivation substrate of $A$. cochinchinensis tissue-cultured seedlings has a low survival rate; on the other hand, as a result of adding coconut bran or peat, vermiculite and perlite, its survival rate and biomass have significantly increased. Peat or coconut bran composite substrate can be used in the process of large-scale seedling cultivation of $A$. cochinchinensis tissue-cultured seedlings.

\section{Underground}

It can be seen from Figure 3 that there are obvious differences in root development under different combinations of substrates. Compared with other combination substrates, T2 and T6 had uniform root distribution, large amounts of roots and many branches, the foundation begins to expand into spindle root tubers and the root tip was bright white; T7 and T5 had moderate rooting and similar root growth; $\mathrm{T} 3$ and T4 had few hairy roots, and the taproot was thick and hard; T1 had the least number of roots and branches, with short and thick roots and poor growth. Overall, the root system of tissue-cultured seedlings of A. cochinchinensis grew well in T2 and T6 combined substrate. At the same time, it was found that the apex of primary roots of tissue-cultured seedlings expanded to initially form root tubers, and fibrous roots grew at the top of root tubers, interspersed and wound in the soil to form a network to fix and absorb water and nutrients.

The effects of different combination substrates on the root parameters of $A$. cochinchinensis tissuecultured seedlings are quite different. It can be seen from Figure 4 that after 60 days of fixed value, the fresh weight, dry weight, length, surface area, diameter and volume of $A$. cochinchinensis tissue-cultured seedling roots of T6 combined substrate species were the largest, and amounted to $4.51 \mathrm{~g}, 0.52 \mathrm{~g}, 935.69 \mathrm{~cm}$, $162.43 \mathrm{~cm}^{2}, 0.72 \mathrm{~mm}$ and $2.47 \mathrm{~cm}^{3}$, respectively, which were significantly higher than those of other treatments $(p<0.05)$. The underground parameters of T2 combined substrate are less than those of T6, which is less different from other combined matrices; the fresh weight, dry weight, length, surface area, diameter and volume of roots were $0.53 \mathrm{~g}, 0.06 \mathrm{~g}, 396.63 \mathrm{~cm}, 51.74 \mathrm{~cm}^{2}, 0.38 \mathrm{~mm}$ and $0.62 \mathrm{~cm}^{3}$, respectively. In conclusion, T6 combined substrate was suitable for the root growth of tissuecultured seedlings of $A$. cochinchinensis, followed by 

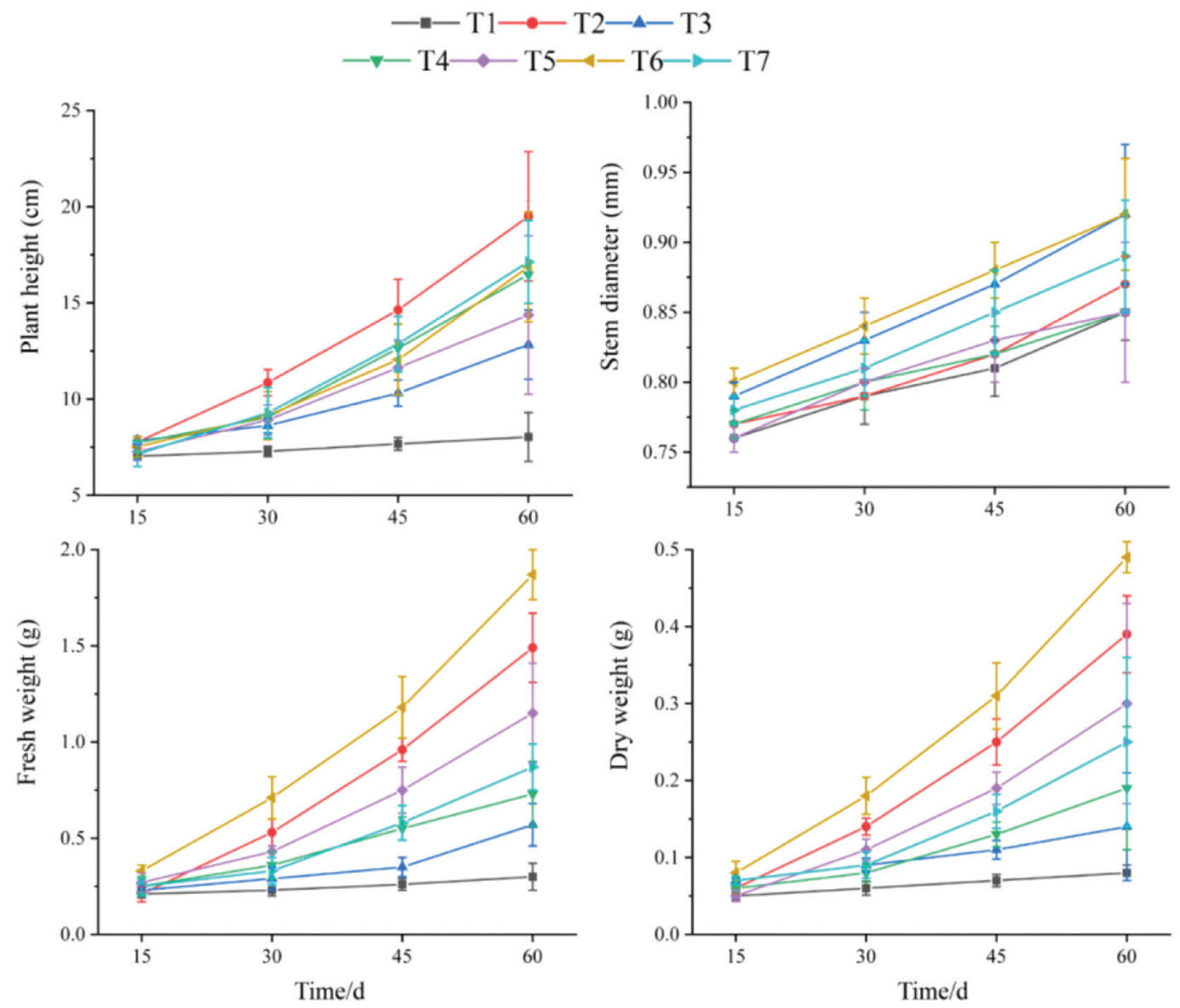

Figure 2. Effects of different combined substrates on above-ground growth of $A$. cochinchinensis. Error bars represent $\mathrm{SD}$ and data in the graphs are the means \pm standard deviation. T1: garden soil 100\%; T2: garden soil: perlite: coconut bran $=20 \%: 40 \%: 40 \%$; T3: garden soil: coconut bran: vermiculite $=20 \%: 40 \%: 40 \%$; T4: garden soil: vermiculite: peat $=20 \%: 40 \%: 40 \%$; T5: garden soil: perlite: peat $=20 \%: 40 \%: 40 \%$; T6: perlite: coconut bran: vermiculite $=$ 33.33\%: 33.33\%: 33.33\%; T7: perlite: vermiculite: peat $=33.33 \%: 33.33 \%: 33.33 \%$.
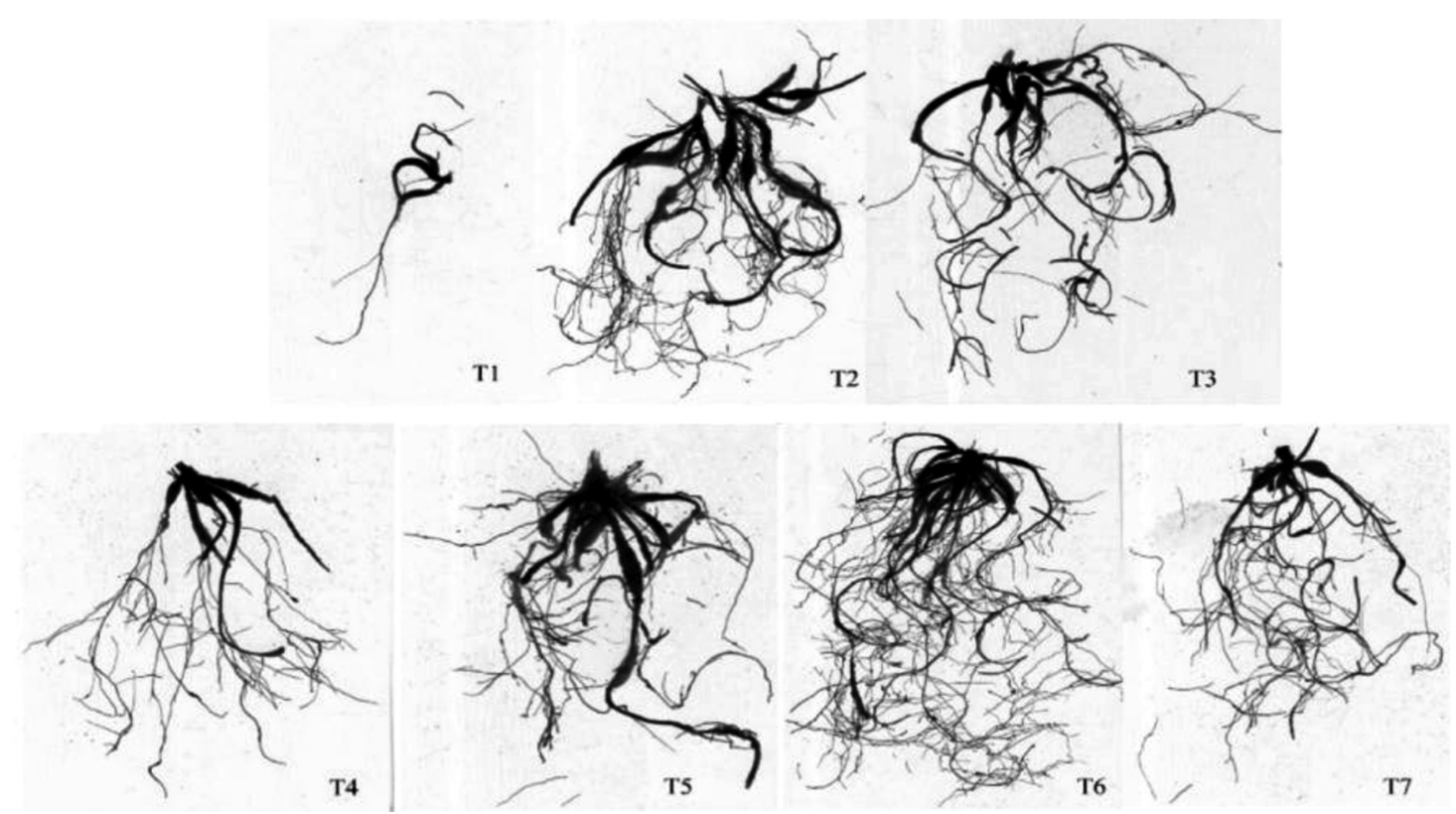

Figure 3. Root morphology of $A$. cochinchinensis plantlet in different substrates. T1: garden soil 100\%; T2: garden soil:perlite:coconut bran $=20 \%: 40 \%: 40 \%$; T3: garden soil:coconut bran:vermiculite $=20 \%: 40 \%: 40 \%$; T4: garden soil:vermiculite:peat $=20 \%: 40 \%: 40 \%$; T5: garden soil:perlite:peat $=20 \%: 40 \%: 40 \%$; T6: perlite:coconut bran:vermiculite $=33.33 \%: 33.33 \%: 33.33 \%$; T7: perlite:vermiculite:peat $=33.33 \%: 33.33 \%: 33.33 \%$. 

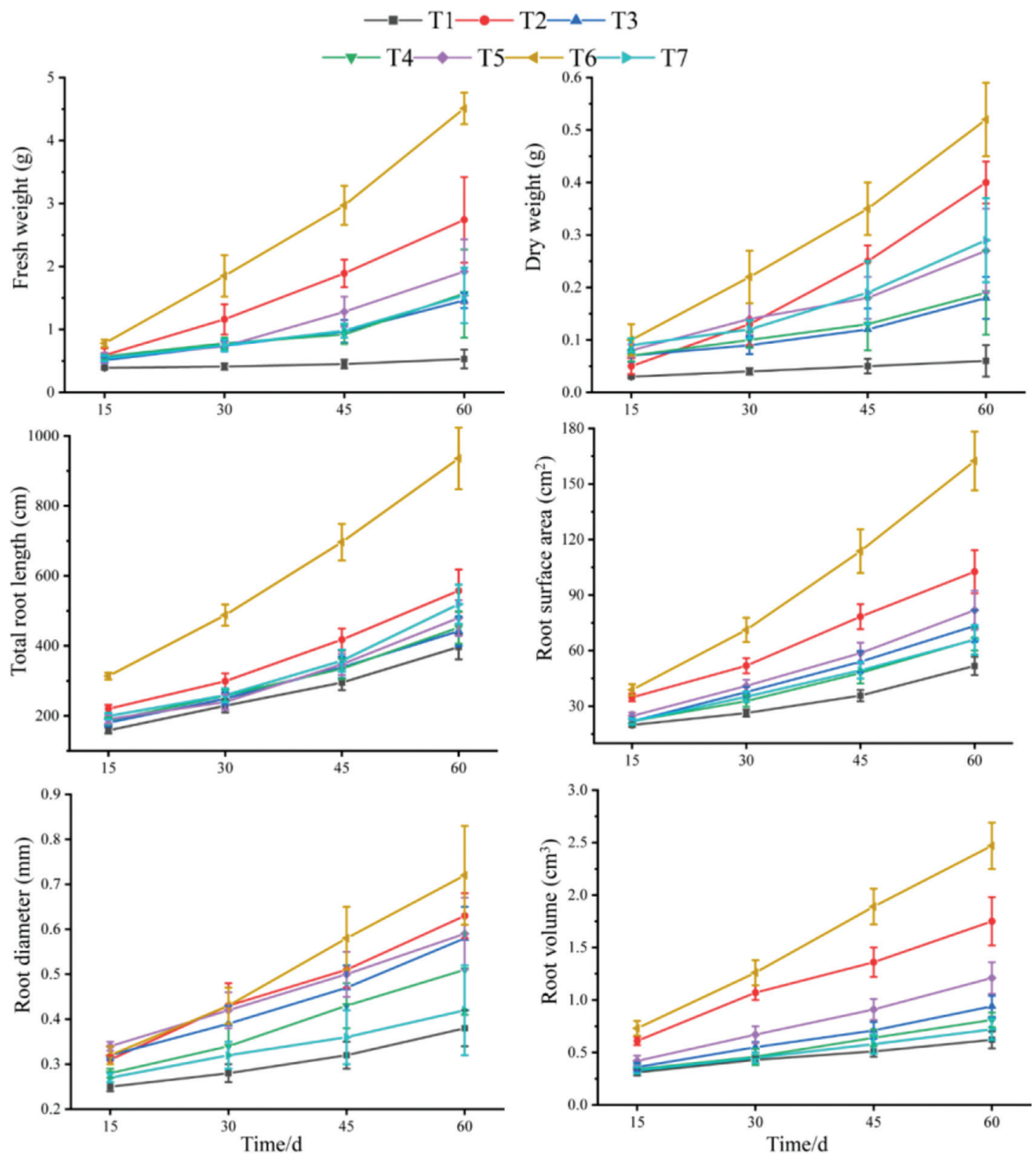

Figure 4. Effects of different combined substrates on underground parameters of $A$. cochinchinensis. Error bars represent $\mathrm{SD}$ and data in the graphs are the means $\pm \mathrm{SD}$. T1: garden soil 100\%; T2: garden soil:perlite:coconut bran $=$ 20\%:40\%:40\%; T3: garden soil:coconut bran:vermiculite $=20 \%: 40 \%: 40 \%$; T4: garden soil:vermiculite:peat $=$ 20\%:40\%:40\%; T5: garden soil:perlite:peat $=20 \%: 40 \%: 40 \% ;$ T6: perlite:coconut bran:vermiculite $=$ 33.33\%:33.33\%:33.33\%; T7: perlite:vermiculite:peat $=33.33 \%: 33.33 \%: 33.33 \%$. SD, standard deviation.

T2, while T1 combined substrate was not conducive for root growth.

\section{Physiology and biochemistry}

Different combinations of substrates had significant effects on soluble protein, soluble sugar, proline, MDA, total chlorophyll content and root vigour of tissue-cultured seedlings of $A$. cochinchinensis (Figure 5). The content of MDA was the highest in $\mathrm{T} 1$, reaching $0.47 \mathrm{mmol} \cdot \mathrm{L}^{-1}$, which was significantly different from T2, T5, T6 and T7. The highest content of total chlorophyll was in $\mathrm{T} 2$, up to $2.24 \mathrm{mg} \cdot \mathrm{g}^{-1}$, which was significantly different from other combinations. The highest proline content was in
$\mathrm{T} 2$, reaching $13.63 \mu \mathrm{g} \cdot \mathrm{g}^{-1}$, which was significantly different from T1, T3, T4, T5 and T7 substrate, but not significantly different from T6 substrate. The content of soluble protein was still the highest in T2, reaching $0.53 \mathrm{mg} \cdot \mathrm{g}^{-1}$, which was significantly different from $\mathrm{T} 1$, but not significantly different from other combinations. T6 had the highest soluble sugar content and root vigour with $1.20 \mathrm{mg} \cdot \mathrm{g}^{-1}$ and $221.42 \mu \mathrm{g} \cdot \mathrm{g}^{-1} \cdot \mathrm{h}^{-1}$, respectively, which were significantly different from other substrates. In conclusion, the physiology and biochemistry value of $A$. cochinchinensis tissuecultured seedlings in T2 and T6 substrates are higher, and also significantly different from those of other combined substrates. 

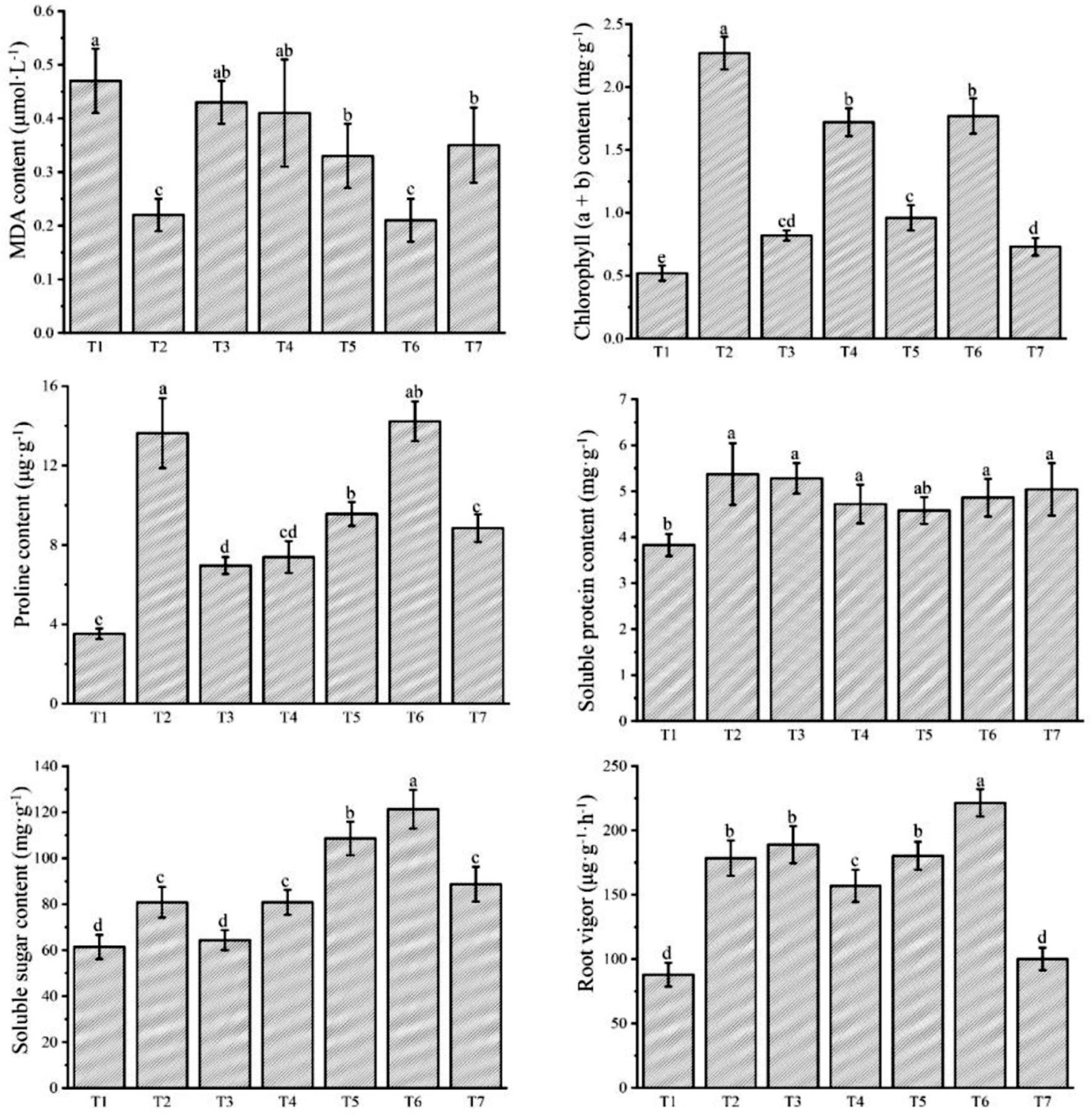

Figure 5. Effects of different combined substrates on physiology and biochemistry indexes of $A$. cochinchinensis. Different lowercase letters indicate significant differences between treatments $(p=0.05)$. Error bars represent SD and data in the graphs are the means \pm SD. T1: garden soil 100\%; T2: garden soil:perlite: coconut bran $=20 \%: 40 \%: 40 \%$; T3: garden soil:coconut bran:vermiculite $=20 \%: 40 \%: 40 \%$; T4: garden soil:vermiculite:peat $=20 \%: 40 \%: 40 \%$; T5: garden soil:perlite:peat $=20 \%: 40 \%: 40 \%$; T6: perlite:coconut bran:vermiculite $=33.33 \%: 33.33 \%: 33.33 \%$; T7: perlite:vermiculite:peat $=33.33 \%: 33.33 \%: 33.33 \%$. SD, standard deviation .

\section{Correlation analysis}

It can be seen from Table 3 that the survival rate of A. cochinchinensis has a negative correlation with the bulk density and conductivity of the substrate $(p<0.01)$, and a positive correlation with the total porosity and aeration porosity $(p<0.05)$. At the same time, the bulk density of substrate was negatively correlated with the plant height, the root dry weight and the content of proline $(p<0.05)$. The soluble protein of $A$. cochinchinensis was positively correlated with water holding pore $(p<0.05)$, and the soluble sugar was positively correlated with aeration pore and airwater ratio $(p<0.05)$. It can be seen that the physical properties such as substrate bulk density, total porosity and EC are closely related to the growth of tissuecultured seedlings of $A$. cochinchinensis. In conclusion, reducing the bulk density of the substrate, increasing the porosity in the substrate and increasing the air capacity of the substrate are more conducive to the growth of A. cochinchinensis roots, stems and branches, and greatly improve the transplantation survival rate of $A$. cochinchinensis tissue-cultured seedlings.

\section{Comprehensive analysis}

The membership function method is used to comprehensively evaluate the quality of A. cochinchinensis seedlings in each substrate. The larger the average membership function value, 
Table 3. Correlation analysis between physical properties of substrate and growth parameters and physiology and biochemistry indexes of tissue-cultured seedlings of $A$. cochinchinensis.

\begin{tabular}{lccccccr}
\hline Index & $\begin{array}{c}\text { Bulk } \\
\text { density }\end{array}$ & $\begin{array}{c}\text { Total } \\
\text { porosity }\end{array}$ & $\begin{array}{c}\text { Aeration } \\
\text { porosity }\end{array}$ & $\begin{array}{c}\text { Water retaining } \\
\text { porosity }\end{array}$ & $\begin{array}{r}\text { Void } \\
\text { ratio }\end{array}$ & $\begin{array}{c}\text { Conductivity } \\
\text { value }\end{array}$ & $\begin{array}{c}\mathrm{pH} \\
\text { value }\end{array}$ \\
\hline Survival rate & $-0.987^{* *}$ & $0.912^{* *}$ & $0.771^{*}$ & 0.517 & 0.668 & $-0.952^{* *}$ & 0.729 \\
Aboveground & & & & & & & \\
Plant height & $-0.853^{*}$ & 0.730 & 0.631 & 0.395 & 0.538 & -0.754 & 0.579 \\
Stem diameter & -0.464 & 0.600 & 0.244 & 0.692 & 0.086 & -0.393 & 0.486 \\
Fresh weight & -0.701 & 0.608 & 0.593 & 0.239 & 0.505 & -0.555 & 0.524 \\
Dry weight & -0.716 & 0.617 & 0.629 & 0.207 & 0.547 & -0.563 & 0.559 \\
Underground & & & & & & & \\
Root fresh weight & -0.658 & 0.653 & 0.537 & 0.390 & 0.410 & -0.525 & 0.557 \\
Root dry weight & $-0.773^{*}$ & 0.698 & 0.648 & 0.319 & 0.544 & -0.613 & 0.631 \\
Root length & -0.555 & 0.597 & 0.553 & 0.274 & 0.440 & -0.407 & 0.629 \\
Root surface area & -0.553 & 0.569 & 0.448 & 0.366 & 0.323 & -0.418 & 0.486 \\
Root diameter & -0.598 & 0.596 & 0.308 & 0.599 & 0.163 & -0.551 & 0.287 \\
Root volume & -0.508 & 0.482 & 0.361 & 0.334 & 0.247 & -0.364 & 0.359 \\
Physiology & & & & & & & \\
Soluble protein & -0.749 & 0.696 & 0.315 & $0.758^{*}$ & 0.175 & -0.698 & 0.375 \\
Soluble sugar & -0.692 & 0.648 & $0.827 *$ & -0.004 & $0.795^{*}$ & -0.637 & 0.715 \\
MDA & 0.681 & -0.543 & -0.544 & -0.193 & -0.470 & 0.505 & -0.465 \\
Total chlorophyll & -0.449 & 0.373 & 0.171 & 0.404 & 0.057 & -0.350 & 0.129 \\
Proline & $-0.760^{*}$ & 0.648 & 0.566 & 0.342 & 0.466 & -0.609 & 0.509 \\
Root vigour & -0.568 & 0.610 & 0.252 & 0.697 & 0.097 & -0.580 & 0.248 \\
\hline
\end{tabular}

*Means significant $(p<0.05)$.

**Means extremely significant $(p<0.01)$.

MDA, malondialdehyde.

Table 4. Membership function values and comprehensive ranking.

\begin{tabular}{|c|c|c|c|c|c|c|c|}
\hline \multirow[t]{2}{*}{ Evaluation index } & \multicolumn{7}{|c|}{ Membership function values of each evaluation index of seven substrates } \\
\hline & $\mathrm{T} 1$ & $\mathrm{~T} 2$ & T3 & T4 & T5 & T6 & T7 \\
\hline Survival rate & 0.00 & 0.95 & 0.78 & 0.76 & 0.90 & 0.98 & 1.00 \\
\hline \multicolumn{8}{|l|}{ Aboveground } \\
\hline Plant height & 0.00 & 1.00 & 0.42 & 0.74 & 0.55 & 0.77 & 0.79 \\
\hline Stem diameter & 0.00 & 0.29 & 1.00 & 0.00 & 0.00 & 1.00 & 0.57 \\
\hline Fresh weight & 0.00 & 0.76 & 0.17 & 0.27 & 0.54 & 1.00 & 0.36 \\
\hline Dry weight & 0.00 & 0.75 & 0.15 & 0.27 & 0.53 & 1.00 & 0.41 \\
\hline \multicolumn{8}{|l|}{ Underground } \\
\hline Root fresh weight & 0.00 & 0.56 & 0.23 & 0.26 & 0.35 & 1.00 & 0.25 \\
\hline Root dry weight & 0.00 & 0.75 & 0.25 & 0.29 & 0.46 & 1.00 & 0.51 \\
\hline Total root length & 0.00 & 0.26 & 0.08 & 0.08 & 0.12 & 1.00 & 0.19 \\
\hline Root surface area & 0.00 & 0.46 & 0.20 & 0.13 & 0.27 & 1 & 0.13 \\
\hline Root diameter & 0.00 & 0.83 & 0.47 & 0.36 & 0.52 & 1.00 & 0.23 \\
\hline Root volume & 0.00 & 0.61 & 0.17 & 0.10 & 0.32 & 1.00 & 0.05 \\
\hline \multicolumn{8}{|l|}{ Physiology } \\
\hline Soluble protein & 0.00 & 1.00 & 0.98 & 0.65 & 0.71 & 0.60 & 0.87 \\
\hline Soluble sugar & 0.00 & 0.29 & 0.11 & 0.29 & 0.82 & 1.00 & 0.47 \\
\hline MDA & 0.00 & 0.964 & 0.15 & 0.23 & 0.54 & 1 & 0.46 \\
\hline Total chlorophyll & 0.00 & 1.00 & 0.17 & 0.70 & 0.28 & 0.75 & 0.15 \\
\hline Proline & 0.00 & 0.94 & 0.32 & 0.36 & 0.56 & 1.00 & 0.50 \\
\hline Root vigour & 0.00 & 0.87 & 1.00 & 0.67 & 0.88 & 0.97 & 0.13 \\
\hline Average value & 0.00 & 0.72 & 0.39 & 0.36 & 0.49 & 0.95 & 0.42 \\
\hline Ranking & 7 & 2 & 5 & 6 & 3 & 1 & 4 \\
\hline
\end{tabular}

T1: garden soil 100\%; T2: garden soil:perlite:coconut bran $=20 \%: 40 \%: 40 \%$; T3: garden soil:coconut bran:vermiculite $=20 \%: 40 \%: 40 \%$; T4: garden soil:vermiculite: peat $=20 \%: 40 \%: 40 \%$; T5: garden soil:perlite:peat $=20 \%: 40 \%: 40 \%$; T6: perlite:coconut bran:vermiculite $=33.33 \%: 33.33 \%: 33.33 \%$; T7: perlite:vermiculite:peat $=33.33 \%: 33.33 \%: 33.33 \%$.

MDA, malondialdehyde. 


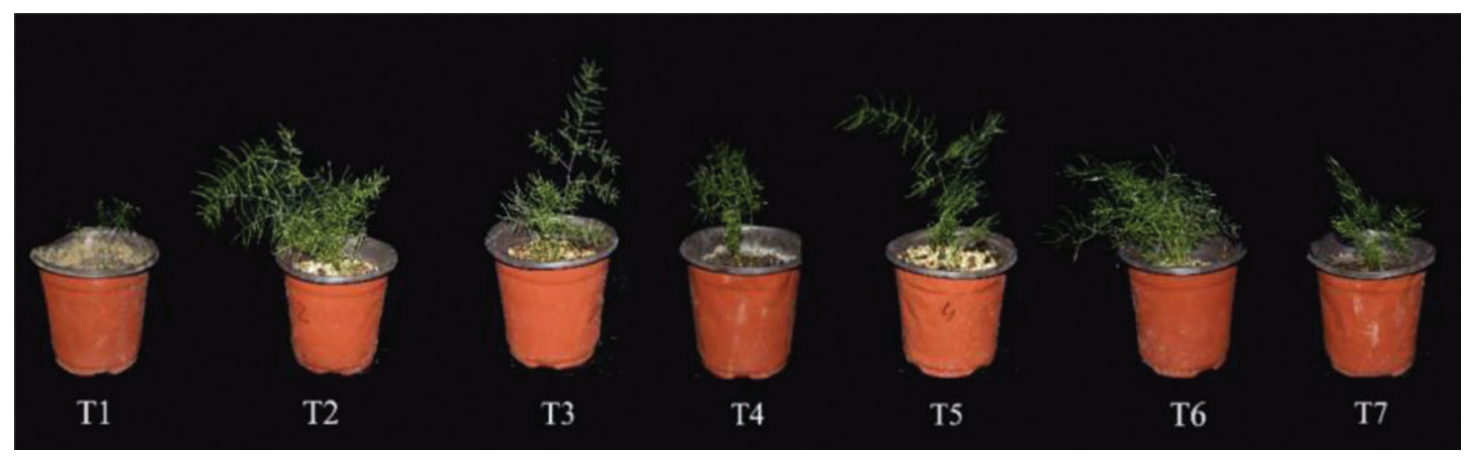

Figure 6. Growth status of $A$. cochinchinensis plantlet in different substrates. T1: garden soil 100\%; T2: garden soil:perlite:coconut bran $=20 \%: 40 \%: 40 \% ;$ T3: garden soil:coconut bran:vermiculite $=20 \%: 40 \%: 40 \%$; T4: garden soil:vermiculite:peat $=20 \%: 40 \%: 40 \%$; T5: garden soil:perlite:peat $=20 \%: 40 \%: 40 \%$; T6: perlite:coconut bran:vermiculite $=33.33 \%: 33.33 \%: 33.33 \%$; T7: perlite:vermiculite:peat $=33.33 \%: 33.33 \%: 33.33 \%$.

the more suitable the substrate is for the growth of A. cochinchinensis tissue-cultured seedlings and the better the quality of seedlings. Table 4 presents the comprehensive evaluation results. The comprehensive scores of $A$. cochinchinensis seedlings cultivated with different substrates are as follows: $\mathrm{T} 6>\mathrm{T} 2>\mathrm{T} 5>\mathrm{T} 7>\mathrm{T} 3>\mathrm{T} 4>\mathrm{T} 1$; the comprehensive scores of all treatments were better than T1. T6 scored the highest, indicating that the growth condition of $A$. cochinchinensis seedlings under T6 combined substrate was the best and the seedling quality was better than other treatments. The growth of tissue-cultured seedlings of $A$. cochinchinensis in each combination substrate is shown in Figure 6, from which it is possible to intuitively ascertain the difference in shoot growth of each treatment. The growth of shoot and leafy branches in the T6 combination substrate is balanced, and so it is most suitable for the growth of tissue-cultured seedlings of $A$. cochinchinensis.

\section{DISCUSSION}

Soil is the material basis for plant growth. It plays the role of fixed support, water retention and air permeability, provides stable and appropriate conditions such as water, gas and nutrition for plant roots and directly affects plant growth and development (Atiyeh et al., 2000). Suitable physical and chemical properties are conducive to plant growth. In practical applications, several substrates are often combined to make the bulk density, porosity, $\mathrm{pH}$ and conductivity of the cultivation substrate reach the appropriate range, so as to improve the survival rate of seedlings. Except for T1 substrate (garden soil), the survival rate of each substrate was $>80 \%$, and the survival rate of T7 (peat:perlite:vermiculite $=33.33 \%: 33.33 \%: 33.33 \%$ ) and T6 (coconut bran:perlite:vermiculite $=33.33 \%: 33.33 \%$ : $33.33 \%$ ) was the highest. Adding the combined substrate of coconut bran to the strong seedling cultivation of ginger seedlings improved the survival rate of seedling transplantation (Mohd et al., 2015). The addition of a combined substrate of peat also improved the survival rate and growth of purslane (Portulaca oleracea L.) (Cros et al., 2007). However, considering the environmental and cost factors, coconut bran is renewable in a short time and the relative cost of using coconut bran is less, while peat is difficult to regenerate in a short time, in the absence of sterilisation Pythium spreads easily and the cost is relatively high (Alu'Datt et al., 2019). Combined with the results of this study, the combination substrate of coconut bran:perlite:vermiculite $=33.33 \%: 33.33 \%: 33.33 \%$ was more suitable.

The substrate composition in soilless culture has a significant impact on plant growth (Qiu et al., 2014). Previous studies have used soilless substrates for agricultural production and cultivation. In studies into the cultivation substrates of ginger (Mohd et al., 2015) and strawberry (Recamales et al., 2007), the use of coconut bran was found to be conducive to the growth of crops and the increase of yield. Compared with other substrates, it had better growth status and comprehensive quality and was the best choice for combined substrates. The physical properties of the substrate have a great impact on plant growth (Alves et al., 2011). The root system of the plant is the main absorption organ of fertiliser and water, and so the growth and root vigour of the root system will directly affect the growth and nutritional status of the aboveground of the plant (Vamerali et al., 2021). In this experiment, 60 days after tissue-cultured seedlings of $A$. cochinchinensis were planted, stems and leafy branches were dark green, plant height was high, aboveground fresh weight and dry weight were the largest, root fresh weight and dry weight were the largest, root growth was good, fibrous roots were developed and root vigour and root parameters were the best in T6 substrate. The results showed that it was more suitable for the growth of tissue-cultured seedlings of A. cochinchinensis in the combined substrate of coconut bran, perlite and vermiculite at the volume ratio of $33.33 \%: 33.33 \%: 33.33 \%$. By further analysing the relationship between the physical properties of the substrate and the growth of aboveground and underground of $A$. cochinchinensis, it was found that 
the survival rate of $A$. cochinchinensis was affected by the bulk density, EC, total porosity and aeration porosity of the substrate, indicating that the physical and chemical properties of substrate will cause differences in rhizosphere environment, affect the absorption and utilisation of oxygen and nutrients by roots and directly affect the growth of plants (Ma et al., 2020).

Malondialdehyde is an important indicator of plant membrane lipid peroxidation. When plants are subjected to stress, the MDA content will increase (Farooq et al., 2010). In this experiment, the MDA content in T1 substrate was the highest, indicating that the garden soil had resulted in poor aboveground and underground growth morphology and reduced survival rate. Soluble protein, soluble sugar and proline are osmotic regulators in plants, which often reflect the nutritional status and quality of plants (Zhao et al., 2011; Yu et al., 2016). The chlorophyll content is an indicator of plant photosynthesis (Mandal and Dutta, 2020), and root vigour reflects the strength of the plant underground in absorbing mineral elements from soil to supply the growth of aboveground (Palta and Watt, 2009). These indexes can be used to evaluate the growth status and comprehensive quality of tissue-cultured seedlings. In T6 substrate, A. cochinchinensis had the highest content of soluble sugar and proline and the best root vigour, and the content of chlorophyll and soluble protein was second only to T2, indicating that T6 substrate could improve the nutritional status and quality of $A$. cochinchinensis. Further analysis of the physical and chemical properties of the substrate and physiological value of $A$. cochinchinensis showed that the bulk density, the water-holding pores and airwater ratio of the substrate would affect the indexes of A. cochinchinensis proline, soluble protein and soluble sugar. It was confirmed again that the physical and chemical properties of the substrate would impact the quality of $A$. cochinchinensis.

According to the membership function, the indexes of tissue-cultured seedlings with different combination substrates were comprehensively evaluated. T6 ranked the highest, and its score was significantly higher than that of other substrates, indicating that the T6 combination substrate was more conducive to the improvement of comprehensive quality and growth and development of tissue-cultured seedlings of A. cochinchinensis. Combined with the analysis of physical and chemical properties of the substrate, the reason why it is suitable for the growth of A. cochinchinensis may be that T6 combined substrate (coconut bran:perlite:vermiculite $=33.33 \%: 33.33 \%$ : $33.33 \%$ ) had the characteristics of small bulk density and large pores, indicating that it is conducive to the growth of $A$. cochinchinensis root and shoot in a loose and breathable substrate. However, because the conventional substrate was adopted in this experiment, higher-quality organic components, such as biochar, can be added to further prepare a combined substrate suitable for A. cochinchinensis growth and better quality.

In this experiment, the combined substrates suitable for the growth of tissue-cultured seedlings of $A$. cochinchinensis were screened. It was found that in the combined substrates of coconut bran, perlite and vermiculite with a volume ratio of 33.33\%:33.33\%:33.33\%, the survival rate was high and the root system was developed and grew well. From the comprehensive evaluation of growth parameters, we find that the physiological and biochemical value is better than those of other combined substrates. Therefore, in the tissue-culture and propagation of $A$. cochinchinensis, coconut bran with low cost can be mixed with other common substrates, and this procedure not only has high transplanting efficiency but also is easier for seedling management and field transplantation of A. cochinchinensis tissue-cultured seedlings.

\section{FUNDING}

This study was supported by the National Key Research and Development Program of China (2016YFC0502604), the Major Special Project of Science and Technology Program in Guizhou (2017-5411-06 and 2018-2797), the Project of High-level Innovative Talents in Guizhou (2015-4031), the Construction Project of State Engineering Technology Institute for Karst Desertification Control of China (2012FU125X13), the Construction Program of Biology First-class Discipline in Guizhou (GNYL2017-009) and the Construction Project of Modern Industry Technology system of traditional Chinese Medicinal Materials in Guizhou (GZCYTX-02).

\section{AUTHOR CONTRIBUTIONS}

X.Y., L.L. and M.Z. designed and outlined the research. X.Y., L.L. and Y.L. conducted the experiments. X.Y., L.L. and Z.L. analysed the data and drafted and edited the manuscript. X.Y., L.L., N.Y. and M.Z. provided plant collections. All authors read and approved the manuscript.

\section{CONFLICT OF INTEREST}

The authors declare no conflict of interest.

\section{REFERENCES}

Abad, M., Noguera, P., And Bure's, S. (2001). National inventory of organic wastes for use as growing media for ornamental potted plant production: Case study in Spain. Bioresource Technology, 77, 197-200, doi: 10.1016/S0960-8524(00)00152-8.

Alu'datt, M. H., Rababah, T., Alhamad, M. N., AiTawaha, A. R. M., Gammoh, S., Ereifej, K. I., Ai-Karaki, G., Hamasha, H. R., Tranchant, C. C., AND Kubow, S. (2019). Herbal yield, nutritive 
composition, phenolic contents and antioxidant activity of purslane (Portulaca oleracea L.) grown in different soilless media in a closed system. Industrial Crops and Products, 141, 111746, doi: 10.1016/j.indcrop.2019.111746.

Alves, E. U., Guedes, R. S., Gonçalves, E. P., Viana, J. S., Santos, S. D. S., And Moura, M. F. D. (2011). Effect of temperature and substrate on germination of Peltophorum dubium (Sprengel) Taubert seeds. Acta Scientiarum Biological Sciences, 33(1), 113-118, doi: 10.4025/AcascibiolSci.v33i1.7057.

Arnon, D. I. (1949). Copper enzymes in isolated chloroplasts. Polyphenol oxidase in Beta vulgaris. Plant Physiology, 24, 1-15, doi: 10.1104/pp.24.1.1.

Asmari, S., Zafar, R., and Ahmad, S. (2004). Production of sarsasapogenin from tissue culture of Asparagus racemosus and its quantification by HPTLC. Iranian Journal of Pharmaceutical Research, 3(2), 66-67, doi: 10.22037/ijpr.2010.497.

Atiyeh, R. M., Arancon, N., Edwards, C. A., And Metzger, J. D. (2000). Influence of earthwormprocessed pig manure on the growth and yield of greenhouse tomatoes. Bioresource Technology, 75(3), 175-180, doi: 10.1016/S 09608524(00)00064-X.

Bates, L. S., Waldren, R. P., and Teare, I. D. (1973). Rapid determination of free proline for water-stress studies. Plant and Soil, 39, 205-207, doi: 10.1007/ BF 00018060.

BRADFORD, M. M. (1976). A rapid and sensitive method for the quantitation of microgram quantities of protein utilizing the principle of protein-dye binding. Analytical Biochemistry, 7(72), 248-254, doi: 10.1016/0003-2697(76)90527-3.

Choo, B. K., Kim, D. H., JeOng, J. R., Lim, J. R., And Ryu, J. H. (2005). In vitro growth of shoot derived from shoot tip in Asparagus cochinchinensis (Lour.) Merr. Korean Journal of Medicinal Crop Science, 13(4), 138-140.

Chun, J. M., Cheon, M. S., Moon, B. C., Lee, A. Y., Choo, B. K., And Kim, H. K. (2011). Anti-tumor activity of the ethyl acetate fraction from Asparagus cochinchinensis in HepG2-xenografted nude mice. Journal of the Korean Society for Applied Biological Chemistry, 54(4), 538-543, doi: 10.3839/ jksabc.2011.082.

Cros, V., Martínez-Sánchez, J. J., and Franco, J. A. (2007). Good yields of common purslane with a high fatty acid content can be obtained in a peat-based floating system. HortTechnology, 17(1), 14-20, doi: 10.21273/HORTTECH.17.1.14.

Du, Q., XiaO, H., Li, J., Wang, J. Q., And ZhaO, Y. P. (2020). Screening of wetting agent for peat substrate and its effect on cucumber seedlings. IOP Conference Series Earth and Environmental Science, 453(1), 012079, doi: 10.1088/1755-1315/453/1/012079.

Farooq, M., Wahid, A., Lee, D. J., Cheema, S. A., And Azız, T. (2010). Comparative time course action of the foliar applied glycinebetaine, salicylic acid, nitrous oxide, brassinosteroids and spermine in improving drought resistance of rice. Journal of Agronomy and Crop Science, 196, 336-345, doi: 10.1111/j.1439-037X.2010.00422.x.

Heath, R. L., And Packer, L. (1968). Photoperoxidation in isolated chloroplasts: I. Kinetics and stoichiometry of fatty acid peroxidation. Archives of Biochemistry and Biophysics, 125, 189-198, doi: 10.1016/00039861(68)90654-1.

Jiang, X. H., Zeng, G. P., Ou, L. J., and She, C. W. (2013). An efficient system for the production of the medicinally important plant: Asparagus cochinchinensis (Lour.) Merr. African Journal of Biotechnology, 9(37), 6207-6212, doi: 10.1186/14752859-9-69.

Kim, Y. G., Okello, D., Yang, S., Komakech, R., Rahmat, E., AND Kang, Y. (2021). Histological assessment of regenerating plants at callus, shoot organogenesis and plantlet stages during the in vitro micropropagation of Asparagus cochinchinensis. Plant Cell, Tissue and Organ Culture, 144(2), 1-13, doi: 10.1007/s 11240-02001967-3.

Lee, D. Y., Choo, B. K., Yoon, T., Cheon, M. S., Lee, H. W., Lee, A. Y., And Kim, H. K. (2009). Antiinflammatory effects of Asparagus cochinchinensis extract in acute and chronic cutaneous inflammation. Journal of Ethnopharmacology, 121(1), 28-34, doi: 10.1016/j.jep.2008.07.006.

Lei, L. H., Chen, Y. H., Ou, L. J., Xu, Y. L., And Yu, X. Y. (2017). Aqueous root extract of Asparagus cochinchinensis (Lour.) Merr. has antioxidant activity in D-galactose-induced aging mice. BMC Complementary \& Alternative Medicine, 17(1), 469, doi: 10.1186/s12906-017-1975-x.

Li, L., Li, Y., Zhang, M. S., Peng, S. J., Wu, S. J., Jia, N., Liu, Z., Yu, X. S., And Yang, C. X. (2021). Rapid Propagation in vitro of Asparagus cochinchinensis. Subtropical Plant Science, 50(1), 46-50, doi: 10.3969/j.issn.1009-7791.2021.01.008.

Lim, T. K. (2015). Asparagus cochinchinensis. In T. K. Lim (Ed.), Edible medicinal and non medicinal plants (pp. 620-626). Dordrecht, Netherlands: Springer.

LiU, J., Zhang, Q. X., AND PAN, H. T. (2013). Effects of different coir dust-based substrates on the growth and development of potted Primula saxatilis. Journal of Fujian Agriculture and Forestry University (Natural Science Edition), 42(05), 498-502, doi: 10.13323/j. cnki.j.fafu(nat.sci.).2013.05.020.

Ma, G. X., Mao, H. P., Bu, Q., Han, L. H., Shabbir, A., AND GAO, F. (2020). Effect of compound biochar substrate on the root growth of cucumber plug seedlings. Agronomy, 10(8), 1080, doi: 10.3390/ agronomy10081080.

Mandal, R., And Dutta, G. (2020). From photosynthesis to biosensing: Chlorophyll proves to be a versatile 
molecule-science direct. Sensors International, 1, 100058, doi: 10.1016/j.sintl.2020.100058.

Meerow, A. W. (1995). Growth of two tropical foliage plants using coirdust as a container medium amendment. HortTechnology, 5, 237-239, doi: 10.21273/HORTTECH.5.3.237.

Mohd, Y. S., Manas, M. A., Sidik, N. J., Ahmad, R., And YAACOB, A. (2015). Effects of organic substrates on growth and yield of ginger cultivated using soilless culture. Journal of Tropical Agriculture \& Food Science, 44(3), 63-68.

Morris, D. L. (1948). Quantitative determination of carbohydrates with Dreywood's anthrone reagent. Science, 107, 254-255, doi: 10.1126/ science.107.2775.254.

Palta, J. A., And Watt, M. (2009). Vigorous crop root systems: Form and function for improving the capture of water and nutrients. Crop Physiology, 309-325, doi: 10.1016/B 978-0-12-3744319.00013-X.

Qiu, Z. J., Zou, C. Q., Shi, Z. J., Dai, Y. L., And Xie, R. X. (2014). Effects of different substrate composition on growth of Gesneriaceae plants. Agricultural Science \& Technology, 15(8), 1335-1338, doi: 10.3969/j. issn.1009-4229.2014.08.022.

Recamales, Á. F., Medina, J. L., and Hernanz, D. (2007). Physicochemical characteristics and mineral content of strawberries grown in soil and soilless system. Journal of Food Quality, 30(5), 837-853, doi: 10.1111/j.1745-4557.2007.00154.x.

Shi, L., Du, N. S., Yuan, Y. H., Shu, S., Sun, J., And Guo, S. R. (2016). Vinegar residue compost as a growth substrate enhances cucumber resistance against the Fusarium wilt pathogen Fusarium oxysporum by regulating physiological and biochemical responses. Environmental Science \& Pollution Research International, 23(18), 18277-18287, doi: 10.1007/s 11356-016-6798-7.

Vamerali, T., Panozzo, A., Visioli, G., and Cortivo, C. D. (2021). Root-microbe interactions influencing water and nutrient acquisition efficiency. In Z. Rengel and I. Djalovic (Eds), The root systems in sustainable agricultural intensification (pp. 159-192). Hoboken, NJ, USA: John Wiley \& Sons, Ltd.

Wang, G. H., Lin, Y. M., Jong-Tar, K., Lin, C. P., Chang, C. F., Hsieh, M. C., Cheng, C. Y., and Chung, Y. C. (2019). Comparison of biofunctional activity of Asparagus cochinchinensis (Lour.) Merr. extract before and after fermentation with Aspergillus oryzae. Journal of Bioscience and Bioengineering, 127(1), 59-65, doi: 10.1016/j. jbiosc.2018.06.015.

Wang, L., Zhang, Z. H., Guo, J. Y., Kong, L. G., LiU, S. Y., Liu, X. M., Wang, H. T., Meng, S. Y., And WeI, Y. (2021). Comparison of drought resistance characteristics of 5 different Zanthoxylum bungeanum varieties. Plant Physiology Journal, 57(2), 419-428, doi: 10.13592/j.cnki. ppj.2020.0423.

Yu, X., Yuan, F., Fu, X., and Zhu, D. H. (2016). Profiling and relationship of water-soluble sugar and protein compositions in soybean seeds. Food Chemistry, 196(1), 776-782, doi: 10.1016/j. foodchem.2015.09.092.

Zhang, F., Lu, Y., Qian, W. H., And Pei, Z. F. (2015). Asparagus cochinchinensis (Lour.) Merr. 天冬 (Tiandong, Chinese Asparagus). In Y. Liu, Z. Wang and J.Zhang(Eds), Dietary Chinese herbs (pp. 83-88). Vienna, Austria: Springer, doi: 10.1007/978-3-21199448-1_8.

ZhaO, H. T., Di, L., LiU, P., Xu, Y. Q., Wang, X. Z., Shan, Y. H., and Feng, K. (2011). Effect of earthworm bio-bed treatment on properties of cow manure. Transactions of the Chinese Society of Agricultural Engineering, 27(5), 255-259, doi: 10.1080/00405000.2010.522047.

Zhou, Y., YANG, X., Zhou, S., AND Wang, Y. (2018). Activities of key enzymes in root NADPdehydrogenase system and their relationships with root vigor and grain yield formation in wheat. Scientia Agricultura Sinica, 51(11), 2060-2071, doi: 10.3864/j.issn.0578-1752. 2018.11.004.

Received: October 17, 2021; accepted: February 2, 2022 